\title{
The EcoPanel: designing for reflection on greener grocery shopping practices
}

\author{
Ulrica Bohné $^{1}$, Jorge Luis Zapico ${ }^{1,2}$, Cecilia Katzeff ${ }^{1,3}$
}

\author{
${ }^{1}$ Centre for Sustainable \\ Communications \\ KTH Royal Institute of Technology \\ Stockholm, Sweden
}

\{ubohne, zapico, ckatzeff\}@kth.se

\author{
${ }^{2}$ Media Technology \\ Linnaeus University \\ Växjö, Sweden
}

\author{
${ }^{3}$ Interactive Swedish ICT \\ Eskilstuna, Sweden
}

cecilia.katzeff@tii.se

\begin{abstract}
While the purchases of organic food are increasing rapidly, it accounts for only a small fraction of the total consumption, and there is still a big gap between consumer values awareness and the actual consumption. This article explores how detailed personal feedback could help the households to gain insight and reflect on their consumption, the text presents the design process of developing a prototype, the EcoPanel, in collaboration with a major player on the food retail market. Based on the access to detailed tracking of purchase data, the aim of the design was to provide relevant feedback to facilitate for reflection on the user's own food choices. The design prototype is intended to serve as an instrument for insight and reflection and to bring unconscious aspects of grocery shopping to conscious awareness. Following a research through design approach, this article describes the interdependent steps in designing the EcoPanel and design decisions playing a role for users' critical reflection of their food choice practices. It discusses the intention of each module in providing insight. Finally, we discuss how a social practice perspective may be useful for identifying fruitful future research into the design for more sustainable grocery shopping practices
\end{abstract}

Keywords-food, eco-feedback, sustainable practice, design, organic food.

\section{INTRODUCTION}

The current food production system has a big negative environmental impact, contributing to climate change, biodiversity loss and ecosystem degradation [1]. The primary environmental impact of food (e.g. greenhouse gas emissions) is connected to the production phase [2]. Thus, it matters how food is produced and how inputs to farm production are sourced. Organic production systems focus on reducing the environmental impact of food production by eliminating fertilizers and chemical herbicides and pesticides, working with closing nutrient loops, and improving animal welfare [3]. While it has not been shown beyond doubt that organic food is better for the environment and human health in all respects, there is enough data to suggest considerable benefits $[3,4]$. Therefore, one way for retailers and consumers to work with sustainability issues is to substitute non-organic foods with organic foods. Although the climate aspect and the emission of green house gases (GHG) is a major challenge for food production and consumption in the world, we will not cover the topic in this paper.

While there is an increased awareness on the benefits of organic food production, there is a behaviour gap between the consumer willingness to buy organic food products and the actual purchases [5]. Labels, such as the EU organic and KRAV, regulate the marketing of organic food and assure the consumers that the production has been carried out according to the standards and principles of organic agriculture. Although the consumption of labelled organic food has increased quite rapidly during the last years, the current percentage in Sweden is still only around $4 \%$ of total food consumption [6].

This article will present the design process of creating the EcoPanel, an exploration of how detailed personal feedback and knowledge on organic food coupled with information on how to act upon this information could be used for promoting reflection and closing this gap.

\section{DESIGN FOR CRITICAL REFLECTION}

Households grocery shopping might at first glance seem like a simple and straightforward activity. When breaking down its constituents, though, a complexity soon emerges. Routine elements are mixed with advanced cognitive and emotional processes [7,8]. Since grocery shopping is a frequently done activity that we tend to do under time constraints, there is a strong habitual and routine aspect to it. The food choice cannot therefore mainly be viewed as based on a rational set of decisions, but rather includes a large degree of automatic, unconscious and intuitive aspects. Because of this more implicit and unreflective part of the practice, there is a tendency to stick to a habitual behaviour, and keep on choosing in the same way as one usually does [8,9].

Thus, the habitual and automatic parts of grocery shopping are by nature not reflected upon. As major parts of the food choice practice are based on routine activities they might be closed to alternative types of behaviour [9], unless they are intervened with. An instrument for reflection might constitute such an intervention. The purpose of the design developed in this paper - the EcoPanel - is to serve as an instrument for 
insight and reflection. It aims to bring unconscious aspects of grocery shopping to conscious awareness, thereby making them available for conscious choice. This way of using a design outcome is referred to as reflective design e.g. [10]). Critical reflection has also been defined as "the kind of thinking that consists of turning a subject in the mind and giving it serious and consecutive considerations" [11].

The intention of the EcoPanel is, thus, to play a role for users' critical reflection of their food choice practices. This reflection may refine the assumptions, habits, values and norms that are socially and culturally constructed. The EcoPanel would intervene with the possibility to view the daily consumption from the particular organic and sustainable angle, and therefore impose a norm critical framing of the food consumption.

By affording a critical feedback of the household's consumption and provide information about organic aspects of food production, the EcoPanel intends to enhance the awareness not only about the own consumption, but also about general views on organic food; what it means, why it exists and is demanded. Moreover, the EcoPanel may raise critical questions regarding the assortment, availability of organically produced products as organically produced.

\section{PREVIOUS DESIGN APPROACHES TO ORGANIC FOOD CONSUMPTION}

The research literature contains a few attempts to address how design may play a role for raising awareness of organic food consumption. Recently, the use of interactive technologies for sustainability purposes has attracted an increasing attention from the Human-Computer Interaction (HCI) community $[12,13]$. This includes using interactive technologies for providing environmental information, such as electricity use, visible for providing feedback $[14,15,16]$, and using persuasive techniques such as competition, goal setting, social comparisons, self monitoring, praise, etc. to change behaviour towards sustainability [17].

While much of sustainable interaction design has focused on electricity and energy, there is a growing interest in the area of sustainable food $[18,19]$. Examples of efforts include using technology for visualizing the carbon footprint of food [20], visualizing food-miles [21], and helping users to reflect on food waste $[22,23]$.

Other relevant work on interaction design for promoting organic grocery consumption has directed attention towards the reflective need in grocery shopping. In 2012 there was a workshop at the DIS-conference [24] focusing in ways to promote more environmentally aware, socially inclusive, and healthier food practices through critical reflection. Submissions to the workshop focused on inductive research methodologies acknowledging the complexity of the area. Others focused on the use of social media as a means for provoking critical reflection on food practices [25], the mobile application Ecofriends is such a design attempt [26].

Whereas the work above targets the product choice phase, the design prototype "The Food Planner" focused instead on the planning phase and the choice of different meals [27]. This prototype was designed to visualize alternative food choices and provide a space for households to negotiate food values, while opening up possibilities for changing cooking practices. It was presented on an iPad and had suggestions of daily meals, including direct environmental feedback.

Reitberger et al [28] used tracking of food consumption to encourage reflection on the nutritional content of food. The Nutriflect system was designed and tested during four weeks in eight households. Nutriflect enables users to compare their household's food consumption against the food pyramid or with their own nutritional aims according to their choice. Informants' testimonies indicate that the system fostered reflections on users' own shopping behaviour.

The EcoPanel, presented here, is a prototype for a web application using interactive technology for providing feedback to users about their organic food consumption. The intention is to increase users' knowledge about their consumption patterns and help them in changing their practices and increasing their percentage of organic food consumption. The EcoPanel, thus, intends to increase consumers' knowledge regarding their own purchase of organic food through critical reflection.

A central aspect of the EcoPanel's design is the access to detailed purchase data. Grocery consumers have not had access to their own continuous feedback on their shopping before. Shopping receipts contain data about the particular shopping occasion, but don't provide aggregate data on a continuous long-term basis that could provide feedback about habits and practices. This lack of data is a limiting factor for design interventions in grocery shopping. While electricity data is quantifiable and easy to gather both at an appliance level and at a household level, food consumption data is not available to the users in a way that is easy to reuse in eco-feedback visualizations. Possibilities include saving and manually logging the information [23], having products tagged with RFID tags [29] or having a camera in the fridge [30].

In many cases the detailed purchase data for a household already exists in the databases of supermarkets, as the customers use fidelity cards that identify them. This data is used by supermarkets to gain insight on consumer behaviour and to tailor offers. It is on the other hand not available for the customers. This paper shows how the availability of this data allows creating eco-feedback visualization about personal food consumption and scaling them up to widespread use. The EcoPanel was developed in collaboration with a major grocery chain. Therefore, it has a potential of reaching several millions of households.

\section{A RESEARCH THROUGH DESIGN APPROACH}

This article presents the design of a prototype following a research through design (RtD) approach [31,32]. We use the RtD approach specifically to explore the use of interactive technologies for eco-feedback visualization in the area of organic grocery shopping. Along the lines of RtD, the design process together with the resulting prototype intends to construct new knowledge in this particular area. Frayling [31] defines research through design as the knowledge that is "embodied in the artefact", i.e. knowledge is created and communicated through the artefact. Another distinguishing quality of the RtD approach is its aptitude for exploring and 
speculating [33]. The design of the EcoPanel should be regarded in this light.

\section{DESIGN PROCESS}

How the design process is conducted is central to the understanding of the RtD methodology. As opposed to a linear process, the design process of the EcoPanel was iterative, through loops based on ideas, tests and revisions. The design process was user-centric, with the end-users for the EcoPanel being customers of the grocery store in question. The design process was carried out along the five phases in Table 1.

Table 1: Design phases of Eco Panel

\begin{tabular}{|c|c|}
\hline $\begin{array}{l}\text { Design } \\
\text { phase }\end{array}$ & Description \\
\hline $\begin{array}{l}\text { 1. Design of } \\
\text { concept }\end{array}$ & $\begin{array}{l}\text { Based on information on food } \\
\text { purchase specified on customer } \\
\text { receipts }\end{array}$ \\
\hline $\begin{array}{l}\text { 2. Design of } \\
\text { paper } \\
\text { prototype }\end{array}$ & $\begin{array}{l}\text { Based on workshop within } \\
\text { interdisciplinary project team } \\
\text { (computer science, graphical and } \\
\text { industrial design, HCI, and } \\
\text { psychology) and with grocery chain }\end{array}$ \\
\hline $\begin{array}{l}\text { 3. Focus } \\
\text { group }\end{array}$ & $\begin{array}{l}\text { Discussions with selected } \\
\text { potential users on their views on } \\
\text { issues regarding food purchase } \\
\text { practices }\end{array}$ \\
\hline $\begin{array}{l}\text { 4. User } \\
\text { evaluation }\end{array}$ & $\begin{array}{l}\text { Potential user groups evaluate } \\
\text { paper prototypes. Evaluations are } \\
\text { combined } \\
\text { interviews to further inform the } \\
\text { design }\end{array}$ \\
\hline $\begin{array}{l}\text { 5. Functional } \\
\text { prototypes }\end{array}$ & $\begin{array}{l}\text { Iterative process where } \\
\text { prototypes are user evaluated and } \\
\text { revised }\end{array}$ \\
\hline
\end{tabular}

The numbering of the phases in Table 1 indicates that the phases were more or less dependent on each other, although quite loosely formalized.

After the initial concept formation stage, the content and messages that the design would communicate were formulated. A design of the content was sketched in multiple versions in paper prototypes, subsequently evaluated by potential users (phase 3 and 4).

In phase 3 - the focus group - we asked informants to contribute with their knowledge and reflections on their habits for planning, organizing and shopping groceries. They were, thus, framed as experts on their own food choice practice. In this way, the meaning of EcoPanel would be grounded in a real world context. In phase 4 informants evaluated the EcoPanel in terms of usability. They evaluated the paper prototype from different aspects: comprehensibility, relevance of the information and the ease of use of the paper prototype.
Design decisions for the functional prototype development were based on results from the focus group discussion in phase 3 ; the varying expertise in the group; and on literature from the area of sustainable HCI. Design for reflection was a guiding principle. To allow users to reflect upon their food choice, the following assumptions concerning the type of feedback users could need were expressed:

- Feedback on the amount of their own organic grocery purchase in the past compared to their total purchase

- Feedback on the variation of the amount of their total purchase and of organic grocery purchase over time

- Feedback on the variation of the amount of organic grocery purchases divided into product categories

- Information on how to make the greatest impact on the environment through the type of groceries they buy and feedback on their own purchase of these groceries.

- General knowledge on the value of organic groceries.

Based on these assumptions a design space of possible modules was defined and a set of these were selected and designed. In total 15 different modules were designed, reflecting our ideas both in regard of content and possible forms. Since we also wanted to explore more broadly how the data could be expressed, we widened the scope at one of the modules and sketched five versions, with different kinds of expressions.

In the first loop of phase 5, the prototype was discussed and tested together with the users. This included technical testing of the prototype. Results were analysed, and based on the analysis a new prototype was created. The process was continued by a second loop where this new prototype was tested. These iterative loops were generated until a wished result had been achieved.

\section{FINAL PROTOTYPE}

The final prototype is a fully functional web application developed using a combination of different web technologies ${ }^{1}$. The website is available online and the users can login using their membership ID and a password. The only requirement to get access to the application is to be a registered customer and to have access to a computer. The information shown is on household level (the data is aggregated for all the persons in a common household).

The application gets daily data about the users purchases at the supermarket chain at a product level (each product purchased is a data point). The data available from the purchases includes user identification, date of purchase, and a list of all the products purchased including: product name, product category, product price, and information if the product is organic certified or not.

1 It is developed in JavaScript, using Node.js as software platform, MongoDB as database, and the JavaScript library D3.js for the visualizations. 
The focus of the design was decided to be on organic food, using organic certification and money spent as basis of the feedback provided. Other aspects such as food miles or carbon emissions are not included because data quality issues. The place of origin is not available for many products, and calculating environmental impact of food products have to rely on LCA (life cycle analysis) that are usually based on generic data and usually not available for all products. The amount of money spent, and how much of it is organic, is data that can be provided without adding uncertainties.

The visualization is presented as a single page with different modules that provide different views of the data (See Figure 1).
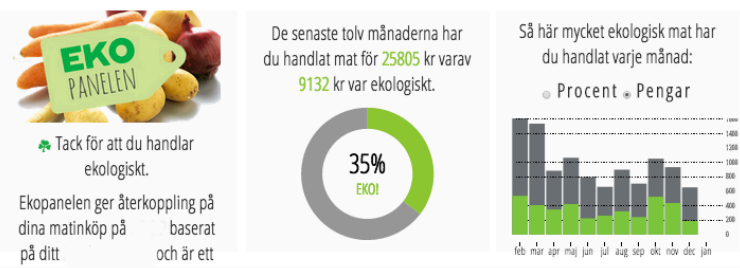

$<$ Mars >

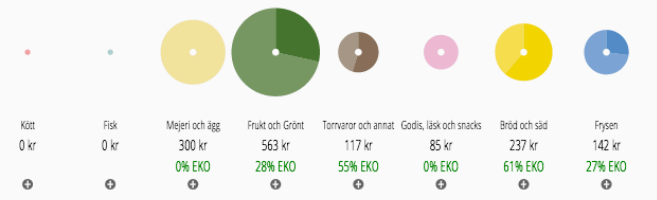

BYT FEM VAROR

Om du inte vet var du ska börja: byt ut dessa fem varor. De gö stor skillad för milï, diur oc storskina for miljö, djur och enniskor om de är ekologis Läs mer om varför. Staplarna till höger visar hur mycket ekologiskt du har hand av dessa varor de senaste 6 månaderna. Pilarna visar utvecklingen
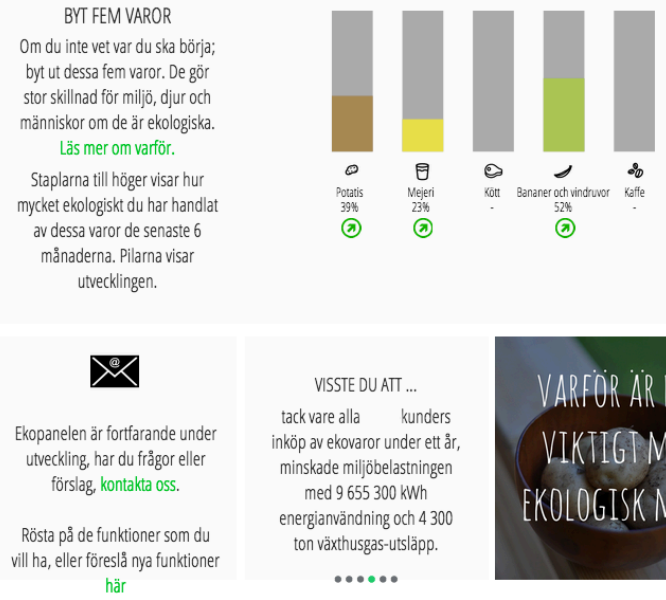

Fig. 1. Overview of the application.

In one of our first user feedback sessions we considered a space of possible design proposals. One proposal was the ability to customize the overall functionality by individually choosing number and types of modules depending on personal needs. Through an adaptive interface the user would be able to pick a preferred module. The overall design would, then, be as complex or simple as wished for. For one individual it might be interesting to only access the total organic percentage, while for another it might be a far more complex interaction. This idea of an individually designed interaction creates conditions for different types of users and user needs, and was well received by the respondents. Since the feature is technically complex, we decided to postpone it for future development.
The existing modules in the final prototype are:

\section{A. Total view}

The first module shows the total amount of money spent during the last twelve months, and which percentage of that was organic. This aims to provide a first overview and give a general insight on the percentage of organic products bought.

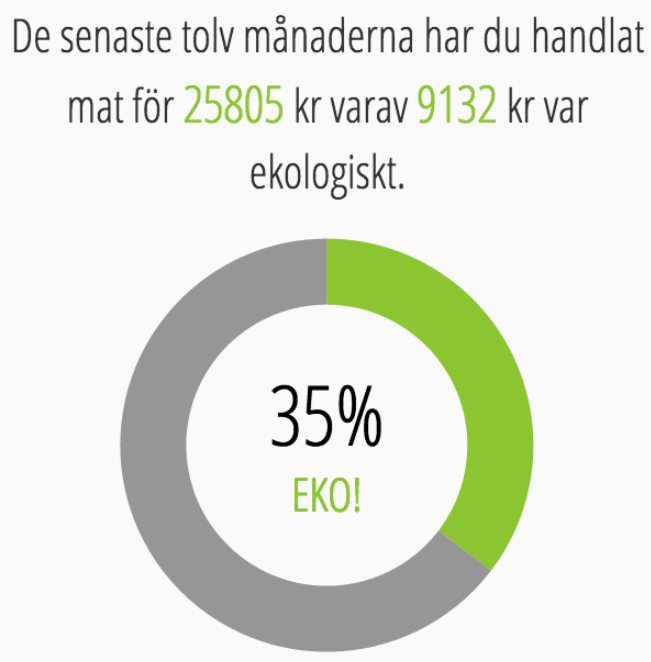

Fig. 2. Total view.

\section{B. Monthly view}

The second module breaks up the total data into different months to provide a time perspective. It shows the money spent and percentage of organic purchases month by month for the last twelve months. The users can select between using an absolute range based on money (see figure 3 ) or a relative range based on percentage (see figure 4).

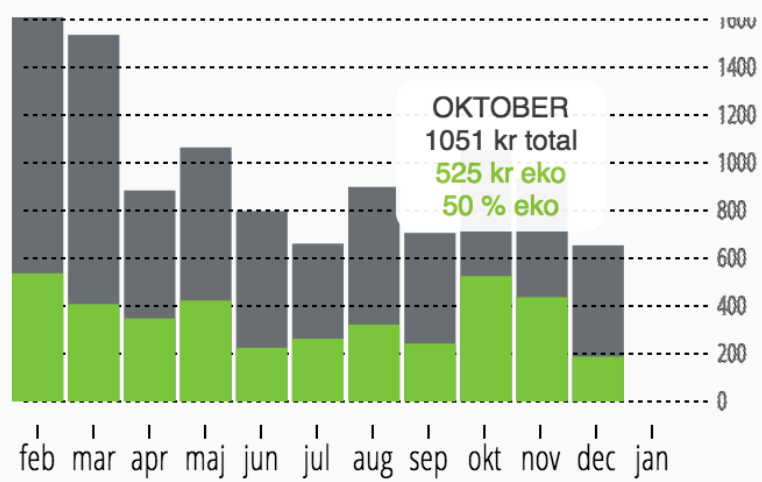

Fig. 3. Monthly view (absolute). 


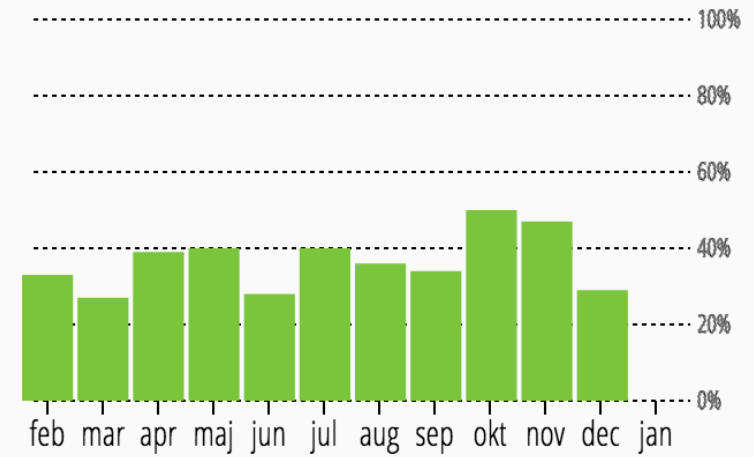

Fig. 4. Monthly view (percentage).

\section{Categories}

The third and biggest module visualizes the purchases per month divided by product categories: meat, fish, dairy and eggs, fruit and vegetables, pantry items, snacks and candy, bread and cereals, frozen food. "Pantry items" is also used as a catch category for items that do not fit the existing categories. This taxonomy is a compromise between the existing business categories and usefulness for the users.

These categories are presented as pie charts with the amount of money spent represented in the area, and the percentage of organic products as a sector of the chart with higher opacity. The user can navigate between the different months using arrows. This feature includes an animation component that transitions the size and ecological percentage between the different months to mark the difference in a clear way. There is also a "plus" button to see the detailed purchases at a product level. This is presented as a text based list of products with their name, price and organic labelling.

The aim of the grocery categories module is to provide a more detailed insight on purchases practices, and to help users to identify categories where they buy mostly organic groceries versus other categories where there may be room for an increase of organic groceries.

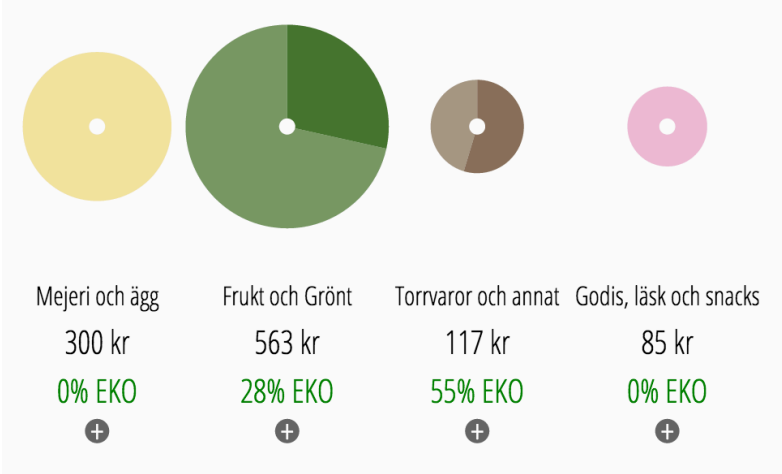

Fig. 5. Part of the categories module.

\section{Five products challenge}

This module shows five different products or categories that are especially important to buy organic [34]: potatoes (high pesticide use), dairy and meat (animal wellbeing), bananas and grapes, and coffee (high pesticide use). The visualization presents the current performance during the last months (how much the user bought organic in that category in percentage), and includes both an arrow showing the trend (increasing, decreasing, equal) and an Eko! symbol if the performance is already outstanding. This module is a more normative view of the data, intended to make the data actionable and aiming to help the users who are motivated to increase their proportion of organic food purchase.

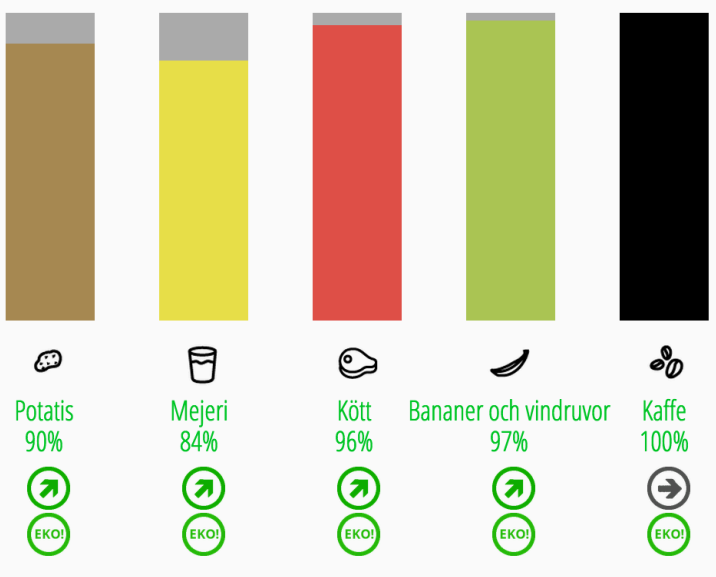

Fig. 6. Five Products Challenge

\section{E. Other}

The application includes additional modules, intended to provide information about the benefits of buying organic food. Links to other sources containing information on organic food are also included. Finally, practical information is presented, such as general information about the application and contact information (See last row of figure 1).

\section{DISCUSSION AND CONCLUSIONS}

\section{A. Feedback and persuasion}

This article presented the design of the EcoPanel, a web application using eco-feedback visualization in the domain of grocery shopping. Based on the access to detailed purchase data, the aim of the design was to provide relevant feedback to facilitate reflection on the user's own food choices. The EcoPanel has a normative intent, as it encourages users to reflect about their food purchases and to increase their proportion of organic food purchases. This can be connected to the use of technology to change personal behaviour proposed by the areas of persuasive technology [35], quantified self ${ }^{2}$ and many applications in sustainable HCI [13], particularly ecofeedback applications [36]. This focus on individual behavioural change has been criticised in sustainable HCI in general by Brynjarsdóttir et al. [37] suggesting that it is not possible to put the responsibility in individual actions without taking into account the social, economical and cultural context. Strengers [38] criticises also the naive believe that information

\section{See an introduction to the quantified-self ideas here:} http://www.economist.com/node/21548493 
by itself is enough for creating sustainability, and that many eco-feedback applications are designed for a non existing ideal, the Resource Man: "Resource Man is interested in his own energy data, understands it, and wants to use it to change the way he uses energy. He responds rationally to [...] detailed data provided about the costs, resource units [...], and impacts." This resource man is the energy representation of the modernist ideas of a "homus economicus" who makes rational choices based on utility and available information, connecting to Brynjarsdóttir et al. [37] discussion about the modernism values inherent in the individual behaviour change of persuasion technologies. In the case of food it gets even more complicated, as food practices have more social, cultural and health components than energy consumption. Ganglbauer et al [30] discuss these complexities in the case of food waste, arguing that food waste is not only a discrete action from individuals but part of complex integrated practices such as cooking and shopping, which are also shaped by existing social and economic structures.

The EcoPanel concept is similar to those that other ecofeedback technologies have explored in the area of energy and electricity. But it can be argued that the intent is different; we don't expect that the mere provision of information and feedback will change users' behaviour. We are aware that the grocery shopping process is complex and based on habits, values, contextual components, and in many cases paradoxes and emotionally grounded decisions. But while providing feedback may not automatically change behaviour, we believe that it can contribute to:

- Gaining insight into practices and aligning mental model of what we think we do, with the reality of what we really do. For instance, the user may think that they spend their money on certain things, or buy a lot of organic food, while the purchase data may reveal another picture. This reflection could help closing the aforementioned gap between the willingness to buy organic food and the actual purchases.

- Providing feedback on possible actions open to users. For instance, users may want to increase their amount of organic food purchases, or change to organic coffee or decrease the amount of candy and snacks, and can then use the application to check the result of the efforts. The intent is not to try to actually persuade anyone into behavioural change that they do not want, but supporting users in the changes they want to make (closing the gap between willingness and action).

The EcoPanel was designed to support these two ways of critical reflection, both by providing an analysis of the past historical data in a long term, to provide insight into patterns and practices, but also allowing to get feedback about changes in the purchase activity.

It is worth reminding that the version in this paper is a prototype, a part of a learning process, and not a final design. In addition to the potential of having user-customized content as discussed earlier, the EcoPanel could come in other formats and platforms. It could, for instance, be presented on terminals in the store. By swiping their membership cards, users could get easy access to their data feedback. This kind of interface could create conditions for different types of user situations.

Alternative representations of the data should also be considered. Instead of the form of bar diagrams, the presentation of data could be more emotional, where the data would be represented in different modalities such as sound, colors, animations, abstract forms etc. This could also be customized to the individual.

\section{B. A social practice perspective}

The complexity of the negative effects of current food production systems must not be under-estimated. To understand how households may play a role in a transition from current food production systems to production systems supporting a sustainable development, we need to understand their role in relation to the whole. A social practice perspective may open up new opportunities for understanding and potentially change everyday practices in a sustainable direction. Although there are several variants of social practice theory, they unite in their view that practices, rather than individuals constitute and mediate social reality [38]. Skills or "shared embodied know-how" constitutes the foundation of practice. Object, technologies or instruments is another point of agreement among different variants of social practice theory.

The social practice perspective entails that human actions are viewed as part of an ecological system rather than isolated phenomena. Also, this perspective is useful to avoid losing sight of the complex system in which households have one important role to play. The actors influence the food choice practice, but also vice versa, the actors are affected by the practice. Relevant actors and components that affect the food choice practice include for instance grocery stores, farmers, agriculture politics, instruments and knowledge, retail policies and distribution, food taste and health characteristics, etc. (see Figure 7).

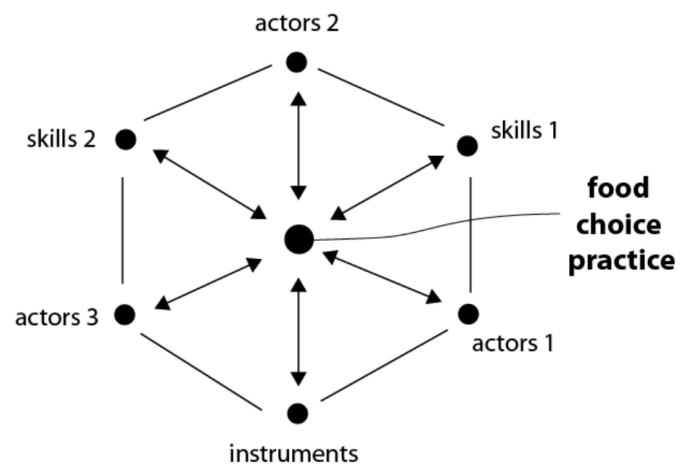

Fig. 7. Interconnection of components affecting food choice practice

One example is the context of grocery stores. Their selection of the organic range, the positioning of the products in the shop, the pricing, etc., are all factors influencing the food choice. However, practice can also put pressure on the stores. If the ecologic products become popular by the consumers, all the mentioned factors would be affected in some way.

This paper presented an approach targeting the retail store, instruments and household practices. We proposed that design might be a powerful instrument in targeting the relationship 
between the retail store and households. Detailed personal feedback and knowledge on organic food coupled with information on how to act upon this information are designed in a web prototype.

The EcoPanel involves a tension between the components of eco-feedback and functionality - common within persuasive and quantified-self technologies - and the complex social and cultural practice that grocery shopping entails. The EcoPanel is one step towards the exploration of this tension. By user participation and looking ahead, we will continue to explore the relationships in the light of social practice theory.

\section{Commercial versus ideologically driven aspects}

Another interesting discussion could be the tension between the commercial versus more ideologically driven aspects that might appear within the grocery chain regarding the use of the EcoPanel. The concept of giving feedback to users on various kinds of consumption, not only the organic parts, enables users to be more in control of their consumption. This might lead to lost profit for the grocery chain, since it might reduce users motivation for buying particular types of groceries, e.g. groceries included in the category "Candy, snacks and soda". Since this category is one of the most profitable for the grocery retailer, tensions might be created within the company regarding the visualization of this type of data.

\section{Future research}

The next step for project is performing a user study with the final prototype for testing the hypotheses that are presented in this article and that are the basis of the design. The application will be tested by a number of users (between 50 to 100) during three months. The evaluation will focus on exploring the users' understanding of their own food purchase practices (with emphasis on organic food choices) and if and how feedback promoted reflection about their practices and affected their understanding. The study will also compare the changes in understanding with actual changes in the purchases practices.

An interesting aspect of the EcoPanel is the possibility of access to detailed quantitative data for evaluation. The user study will use a combination of qualitative and quantitative methods. From a qualitative perspective, we will use questionnaires (both before and after the user uses the application) and interviews, to inquiry about the users own understanding and values. This information can then be correlated with the quantitative information about real users' purchase practices compared to their expected organic purchases. With the existing data about the historical consumption and the data collected during the user test we will also analyse the changes in organic purchase practices, connecting it to the users' values and understanding. The mixed inquiry approach using both qualitative and quantitative methods, will be an interesting way of exploring complex questions such as food purchase practices.

Food consumption is one of the main environmental impacts in our everyday life, but eco-feedback research has mostly focused on electricity and energy, while food has not gotten so much attention due to the more difficult access to data. The design of the EcoPanel presented in this article shows the possibilities of how we can use existing purchase data from supermarkets to provide users insight and feedback about their purchases practices for promoting critical reflection and encourage organic food choices. To create the design we followed an iterative design process that allowed us to include user and expert feedback and to use the design process itself as a tool for inquiry and exploring new possibilities in this field. From the design process and the existing literature we have identified an existing tension between the use of feedback for motivating individual change, and the social and interconnected nature of the practices to be changed. We want to test a middle way and we suggest that a combination of ecofeedback with critical reflection and a social practice perspective can be a way of creating insight and helping close the gap between the users willingness to buy organic food and their practices.

\section{ACKNOWLEDGEMENTS}

The authors are grateful to CESC colleagues and partners and to focus group members who participated in the design of the EcoPanel. We thank the reviewers for helpful comments and Vinnova for a financial grant supporting the project.

\section{REFERENCES}

[1] Foley, J.A., Ramankutty, N., Brauman, K.A., Cassidy, E.S., Gerber, J.S., Johnston, M., Mueller, N.D., O’Connell, C., Ray, D.K., West, P.C., Balzer, C., Bennett, E.M., Carpenter, S.R., Hill, J., Monfreda, C., Polasky, S., Rockström, J., Sheehan, J., Siebert, S., Tilman, D. and Zaks, D.P.M. 2011. Solutions for a cultivated planet. Nature 478, 337-342

[2] Angervall, T., U. Sonesson, F. Ziegler \& C. Cederberg. 2008. Mat och klimat. En sammanfattning om matens klimatpåverkan i ett livscykelperspektiv. SIK-Rapport nr 7762008.

[3] Bengtsson, J., Ahnström, J. and Weibull, A. 2005. The effects of organic agriculture on biodiversity and abundance: a meta-analysis. Journal of Applied Ecology, 2005, 42,2.

[4] Scialabba, N. E-H and Müller-Lindenlauf, M. 2010. Organic agriculture and climate change." Renewable Agriculture and Food Systems 25.02: 158-169.

[5] Vermeir, I. and Verbeke, W. 2006, Sustainable food consumption: Exploring the consumer "attitude -- behavioral intention" gap. J. Agricult. Environ. Ethics 19(2), 169-194.

[6] Ekoweb 2014, Ekologisk livsmedelsmarknad. Rapport om den ekologiska branschen sammanställd av Ekoweb.nu, 30 januari 2014

[7] Franchi, M. 2012. Food choice: beyond the chemical content. International Journal of Food Sciences and Nutrition, 63, 17-28.

[8] Normann, A. 2012. Consumer food choice - How, Why and When? The importance of attitudes, preferences, information, alarm and other factors influencing food choice situations, SIK, PX00357.

[9] Magnusson, M. and Biel, A. 2005. Konsumentens val av miljövänliga livsmedel, Rapport MAT 21nr 7/2005.

[10] Sengers, P., Boehner, K., David, S., \& Kaye, J. J. 2005, Reflective design. In Proceedings of the 4th decennial conference on Critical computing: between sense and sensibility (pp. 49-58). ACM.

[11] Dewey, J. 1997. How we think. Courier Dover Publications

[12] Goodman, E. (2009, April). Three environmental discourses in humancomputer interaction. In CHI'09 Extended Abstracts on Human Factors in Computing Systems (pp. 2535-2544). ACM.

[13] DiSalvo, C., Sengers, P., and Brynjarsdóttir, H. (2010). Mapping the landscape of sustainable HCI. In Proceedings of the 28th international conference on Human factors in computing systems pp. 1975-1984. ACM. 
[14] Gustafsson, A., Katzeff, C. and Bång, M., 2009. Evaluation of a pervasive game for domestic energy engagement among teenagers. In Proceedings of Computers in Entertainment (CIE), ACM, 4; 54:1-54-19.

[15] Broms, L. Katzeff, C., Bång, M., Nyblom Å., Ilstedt-hjelm S. and Ehrnberger, K. 2010. Coffee Maker Patterns and the Design of Energy Feedback Artifacts. Proceedings of the 8th ACM Conference on Designing Interactive Systems (DIS), ACM, Århus, Denmark, 93-102.

[16] Katzeff, C., Broms, L., Jönsson, L., Westholm, U. and Räsänen, M. 2013. "Exploring sustainable practices in workplace settings by visualizing electricity consumption". ACM Transactions on ComputerHuman Interaction, Vol. 20, No. 5, Article 31, ACM Press, November 2013.

[17] Zapico, J.L., Turpeinen, M. 2009. Climate Persuasive Services: Changing behavior towards low-carbon lifestyles. Proceedings of Persuasive 2009: Fourth International Conference on Persuasive Technology. ACM Digital Library.

[18] Blevis, E. and Morse, S. C. 2009. SUSTAINABLY OURS Food, dude. Interactions 16, 2, 58-62.

[19] Hirsch, T. Sengers, P. Blevis, E. Beck, R and Parikh, T. 2010. Making food, producing sustainability. In CHI '10 Extended Abstracts on Human Factors in Computing Systems (CHI EA '10). ACM, New York, NY, USA, 3147-3150.

[20] Clear, A. and Friday, A. 2012. Designing a Food 'Qualculator'. DIS 2012 workshop on Food for Thought: Designing for Critical Reflection on Food Practices. Newcastle, UK. June, 2012.

[21] Kalnikaite, V. Rogers, Y. Bird, J. Villar, N. Bachour, K. Payne, S. Todd, P.M. Schöning, J. Krüger, A. and Kreitmayer, S. 2011. How to nudge in Situ: designing lambent devices to deliver salient information in supermarkets. In Proceedings of the 13th international conference on Ubiquitous computing (UbiComp '11). ACM, New York, NY, USA, 1120.

[22] Thieme, A. Comber, R. Miebach, J. Weeden, J. Kraemer, N. Lawson, S. and Olivier, P. 2012. "We've bin watching you": designing for reflection and social persuasion to promote sustainable lifestyles. In Proceedings of the SIGCHI Conference on Human Factors in Computing Systems (CHI '12). ACM, New York, NY, USA.

[23] Farr-Wharton, G. Foth, M. and Choi, J.Z. 2013. EatChaFood: challenging technology design to slice food waste production. In Proceedings of the 2013 ACM conference on Pervasive and ubiquitous computing adjunct publication (UbiComp '13 Adjunct). 559-562. ACM, New York, NY, USA.

[24] Choi, J.H-j., Linehan, C., Comber, R., and McCarthy, J. 2012. Food for thought: Designing for critical reflection on food practices. Proc. of the Designing Interactive Systems Conference (Newcastle upon Tyne, U.K.). ACM, 2012, 793-794.
[25] Choi, J.H-j., Linehan, C. and Comber, R. 2013. Food for thought: Designing for critical reflection on food Practices. Interactions Jan+Feb, 46-47.

[26] Tholander, J. and Jacobsson, M. 2013, Ecofriends-Designing for critical reflection using social voices. Interactions Jan+Feb, 58-62.

[27] De Jong, A., Kuijer, L. and Rydell, T. 2013. Balancing food values: Making sustainable choices within cooking practices. Nordic Design Research Conference 2013, Copenhagen-Malmö, 127-135.

[28] Reitberger, W., Spreicer, W. and Fitzpatrick, G. 2014. Situated and mobile displays for reflection on shopping and nutritional choices, Pers. Ubit Comput, 18,1721-1735.

[29] Cahier, J. and Gullberg, E. 2008. Ubiquitous Computing: Using everyday object as ambient visualization tools for persuasive design. Master Thesis, Linköping University.

[30] Ganglbauer, E. Fitzpatrick, G. and Comber, R. 2013. Negotiating food waste: Using a practice lens to inform design. ACM Trans. Comput.Hum. Interact. 20, 2, Article 11 (May 2013),

[31] Frayling, C. 1993. 'Research in Art and Design.', Royal College of Art Research Papers series Volume 1 Number 1 1993/4.

[32] Zimmerman, J. 2007. Research Through Design as a Method for Interaction Design Research in HCI, Carnegie Mellon University, Research Showcase CMU.

[33] Gaver, W. 2012. What Should We Expect From Research Through Design? CHI 2012, May 5-10, 2012, Austin, Texas.

[34] SNF. 2014. Fem viktiga varor att byta till eko. (The Swedish Society for Nature Conservation: Five important products to buy organic) http://www.naturskyddsforeningen.se/nyheter/5-viktiga-varor-att-bytatill-eko [Accessed on February 2015]

[35] Fogg, B.J. 2003. Persuasive Technologies. Using computers to change what we think and do. Stanford University. Morgan Kaufmann Publishers.

[36] Froehlich, J., Findlater, L. and Landay, J. 2010. The design of ecofeedback technology. In Proceedings of the SIGCHI Conference on Human Factors in Computing Systems (CHI '10). ACM, New York, NY, USA, 1999-2008.

[37] Brynjarsdóttir, H., Håkansson, M., Pierce, J., Baumer, E., DiSalvo, C., and Sengers, P. 2012. Sustainably Unpersuaded: How Persuasion Narrows our Vision of Sustainability. CHI '12 Proceedings of the 2012 ACM annual conference on Human Factors in Computing Systems, s. 947-956.

[38] Strengers, Y. 2014. Smart Energy in Everyday Life: Are you Designing for Resource Man? Interactions 21, 4 (July 2014), 24-31. 